\title{
Drohnen und das Recht
}

\author{
Völker- und verfassungsrechtliche Fragen automatisierter und autonomer \\ Kriegführung \\ Hrsg. v. Robert Frau
}

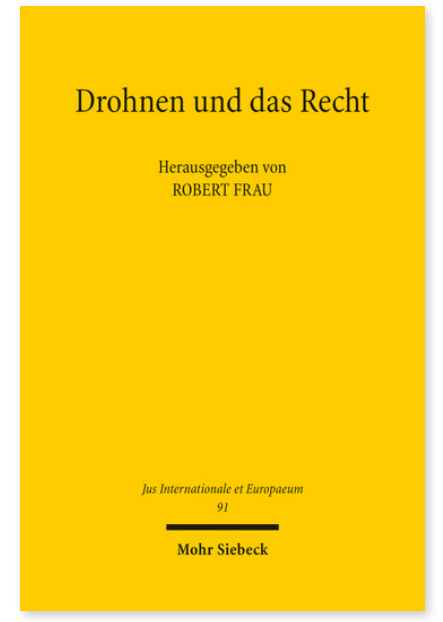

2014. XII, 280 Seiten. JusIntEu 91

ISBN 978-3-16-153284-9

DOI 10.1628/978-3-16-153284-9

eBook PDF 74,00€

ISBN 978-3-16-153140-8

fadengeheftete Broschur 74,00€
Drohnen stehen im Mittelpunkt einer gesellschaftlichen Debatte um moderne Kriegführung. Eine rechtliche Analyse fehlt jedoch häufig. Der Band untersucht die Rechtsfragen, die sich bei zunehmender Automatisierung und »Autonomisierung« stellen. Im Fokus stehen nicht nur Drohnen, sondern auch andere unbemannte Systeme, wie etwa Systeme zur See, Schwärme oder »Killer-Roboter «, die Entscheidungen ohne menschliche Einflussnahme treffen. Thematisch reichen die Beiträge vom humanitären Völkerrecht über Grund- und Menschenrechte bis zum Völkerstrafrecht. Ergänzt wird die völkerrechtliche Perspektive durch verfassungsrechtliche Beiträge, die sich u.a. dem Parlamentsvorbehalt bei Drohneneinsätzen, Staatshaftungsrecht und dem Ankauf von bewaffneten Drohnen durch die Bundeswehr widmen.

\section{Inhaltsübersicht}

Gunter Pleuger: Vorwort - Robert Frau: Vorwort des Herausgebers - Carolin Mahn-Gauseweg: Automated Warfare Operationen unbemannter Systeme. Eine technische Systematisierung - Rieke Arendt: Der Einsatz autonomer Waffensysteme im Lichte des Verhältnismäßigkeits- und des Unterscheidungsgrundsatzes - Olivia Platek: Autonome Kriegsführung und legitime militärische Ziele - Dorota Banaszewska: Kombattanten und Zivilisten weit weg vom Schlachtfeld. Rechtsstellung der Operateure unbemannter militärischer Luftfahrzeuge - Olaf Seiring: Drohneneinsätze gegen feindliche Kämpfer. Besteht eine Pflicht zur Gefangennahme als milderes Mittel? - Marce/ Schulz: Autonomie zur See. Die völkerrechtliche Einordnung von unbemannten militärischen Seefahrzeugen - Tassilo Singer: Chancen und Risiken der Schwarmtechnologie - Philipp Stroh: Das Menschenrecht auf Leben im zunehmend »entmenschlichten« bewaffneten Konflikt - Manuel Brunner: Grundrechtsfragen beim Einsatz von Kampfdrohnen durch die Bundeswehr im Ausland - Simon Gauseweg: Der konstitutive Parlamentsvorbehalt beim Einsatz bewaffneter Drohnen - Udo Moewes: Staatshaftungsrechtliche Implikationen automatisierter Kriegsführung - Jana Hertwig: Bundeswehr und Kampfdrohnen. Empfehlungen für ein sicherheitspolitisches Konzept der Bundesregierung - Robert Frau: Völkerstrafrechtliche Aspekte automatisierter und autonomer Kriegführung - Alexander Schwarz: Terrororganisationen und die Voraussetzungen einer »organisierten bewaffneten Gruppe«. Völkerrechtliche Aspekte der Einordnung von Terroristen als zulässiges militärisches Ziel im Rahmen von Drohneneinsätzen

Robert Frau Geboren 1979; Studium der Rechtswissenschaften an der Europa-Universität Viadrina in Frankfurt (Oder); 2005 Erstes Juristisches Staatsexamen; 2010 Promotion; Rechtsreferendariat in Berlin und New York; 2010 Zweites Juristisches Staatsexamen; Akademischer Mitarbeiter an der Viadrina; 2019 Habilitation und Ernennung zum Privatdozenten ebendort; seit 2017 Lehrstuhlvertretungen an den Universitäten Leipzig, Potsdam, FU Berlin, Marburg und Heidelberg.

\section{Jetzt bestellen:}

https://mohrsiebeck.com/buch/drohnen-und-das-recht-9783161532849?no_cache=1

order@mohrsiebeck.com

Telefon: $+49(0) 7071-923-17$

Telefax: $+49(0) 7071-51104$ 